\title{
USER BEHAVIOUR INTENTION USING UTAUT2 MODEL: A SYSTEMATIC LITERATURE REVIEW
}

\author{
Zahra Fithriya, Alexandri Mohammad Benny, Purnomo Margo, Arifianti Ria, \\ Muftiadi Anang, Herawati Tety, Nugroho Danang, Ruslan Budiana \\ Department of Business Administration, University of Padjajaran, Bandung, Indonesia \\ ${ }^{\star}$ E-mail: fithriya15002@mail.unpad.ac.id \\ ORCID: 0000-0002-2417-7703
}

\begin{abstract}
The development of information communication technology (ICT) and also derivatives of its technology make it easier for the public to conduct online transactions. This study seeks prior research by using systematic literature to look at customer's Behavior Intention by using theories from Unified Theory of Acceptance and Use of Technology 2 (UTAUT2) so as to understand the developments and new discoveries that have emerged in previous studies. A systematic literature review is used in this research methodology so the review can be explained systematically. Based on the findings of this literature review research aspires a method or framework that can be used for researchers as well as practitioners to understand the customer's Behavior Intention by using theories from UTAUT2 so that it can inspire further research.
\end{abstract}

\section{KEY WORDS}

UTAUT2, systematic literature review, behaviour intention, customer.

The faster development of information communication technology (ICT) and smart phones, smart technology and mobile application software (applications) have become a broad and integral part of everyday life (Alalwan, 2020). With more and more users mobile applications are created and designed to be downloaded and used via smartphones or similar mobile platforms (e.g., Android platforms, iPad, tablets). In the first quarter of 2017, the number of applications available globally for download was around 2.2 million using the Apple App Store and 2.8 million for the Google Play Store and users had downloaded more than 178.1 billion applications on their mobile devices in 2017 , the figure is expected to increase to 258.2 billion in 2022 (Alalwan, 2020). More and more users in using this technology become an attractive potential for individual acceptance in information systems research.

To understand individual acceptance in the use of information technology is the most recent research in information systems research (Venkatesh et al, 2012). There are several theoretical models used in developing theories in psychology and sociology used to explain technology acceptance and use. A review and synthesis of eight theories / models of technology use resulted in what is called the Unified theory of acceptance and use of technology (UTAUT, Venkatesh et al., 2003). UTAUT has distilled critical factors and contingencies related to predictions on behavioral intention in using technology. In research on longitudinal field studies specifically on the acceptance of employee technology, UTAUT explained about 70 percent of the variance in behavioral intention to use technology and about 50 percent of the variance in technology use (Venkatesh et al., 2012). In this study, it will explain the definitions, especially for theories related to behavioral intention.

The switch from traditional trade to using this technology is partly due to the advantages of safety, design and content factors are important factors in gaining customer confidence in mobile trading. In addition, consumers can also give a rating or value to customer satisfaction into added value when post-purchase, consumers can immediately conduct an evaluation and they also feel the effectiveness in responding to the entire product and service (Siahaan \& Legowo, 2019). 
In this study, researchers used an analytical approach to find research that has been done about user Behavior Intention using UTAUT 2 Model. The analysis was carried out to find out how to apply the theory that has been used in the user Behavior Intention research using UTAUT 2 Model. Basically, the purpose of this study is to identify user Behavior Intention using UTAUT 2 with systematic literature review, and offer some suggestions or references for future related research (Nugroho et al., 2019). The method of systematic literature review will provide information obtained from previous studies, therefore researchers can provide suggestions based on theory and empirical research. Furthermore, this entire article will discuss the concept of user Behavior Intention using UTAUT 2 Model, an explanation of the research methodology, and the results of a systematic literature review, identifying information obtained and suggestions for use based on theoretical perspectives.

\section{LITERATURE REVIEW}

The concept of the unified theory of acceptance and use of technology (UTAUT, Venkatesh et al., 2003) serves as a basic model and has been applied to various studies that use basic technology in both organizational and non-organizational settings. There is a lot of research on the application and replication of all models or parts of models in organizational settings that have contributed to strengthening generalizations (Venkatesh et al., 2012). There are three types of extensions / integration of the UTAUT concept. The first type of extension / integration that uses the UTAUT concept is to use new contexts, such as new technology (for example, collaborative technology, health information systems), new user populations (for example, health professionals, consumers) and new cultural settings (for example, China, India) (Venkatesh et al., 2012). The second type is to add new constructs to expand the scope of endogenous theoretical mechanisms described in UTAUT (Chan et al., 2008). The last is the third type, which is to carry out the process of inclusion of exogenous predictors from the UTAUT variable. The addition of views in the form applications, and extensions / integrations of UTAUT is valuable in broadening understanding of technology adoption and expanding theoretical boundaries of the theory.

Unified Theory of Acceptance and Use of Technology (UTAUT) is a theory about the acceptance of the latest technology that was first developed by Venkatesh et al., (2003). as a connection of eight previous theories, namely Theory of Reasoned Action (TRA), Theory of Planed Behavior (TPB), Technology Acceptance Model (TAM), Motivational Model (MM), Combined TAM-TPB (C-TAM-TPB ), Model of Personal Computer Utilization (MPCU), Innovation Diffusion Theory (IDT), and Social Cognitive Theory (SCT). The UTAUT model was developed with four types of core constructs, namely expectations for performance (expectancy performance), expectations for effort (social expectancy), social influence (social expectancy), and conditions support (facilitating expectancy). In addition to the four constructs, there are four moderators, namely gender (age), age (age), experience (experience), volunteerism of users (voluntariness of use). In this theory explained by the tendency to behave Behavioral Intention and user behavior (Venkatesh et al., 2003).

According to Venkatesh et al., (2003).the resulting UTAUT model formulates the factors that give rise to system acceptance and usage with four key moderators that influence each other. The factors that give rise to user acceptance in the UTAUT model are: Performance expectancy, namely the level of user confidence that using a system will help users produce maximum work performance. Effort Expectancy, which is the level of ease felt by the user in using a system. Social Influence, i.e. one's awareness of the existence of another person using a system. The constructs that are incorporated in social influence are: Facilitating Conditions, namely the belief that there are organizational and technical facilities that support the use of the system. Behavioral Intention According to Ajzen, (1991) intention to consume is one of the motivational factors that influence behavior. Behavioral Intention is defined as the extent to which someone will use technology services in the future.

Then UTAUT2 was further developed by Venkatesh et al., (2012) by giving special attention to consumers. The UTAUT2 concept adds habit variables as a direct effect on consumers and indirect effects that shape behavioral intention. In this concept Venkatesh et 
al., (2012) are aware that theorized the moderating effects of demographic characteristics on the habit-intention and habit-use relationships. The hypothesis of the UTAUT2 concept adds age, gender, and experience jointly moderate the effect of habit on technology use based on the underlying process of habit activation and enforcement. The fundamental difference between UTAUT and UTAUT2 is by creating new constructions and new relationships that expand the application of UTAUT, with the extensions; this becomes critical to making the predictive validity in a consumer context.

\section{METHOD OF RESEARCH}

The study was conducted with the help of using systematic literature review. This method helps identify and facilitate researchers for literature reviews of previous research. Systematic literature review was adopted from Tranfield et al, (2003), researchers conducted the determination of the inclusion of previous studies in accordance with the research theme and then conducted a process of exclusion of previous studies that were not in accordance with the recommendations of the research theme. The use of this methodology makes it easier for researchers to get comprehensive literature coverage. The methodology from Tranfield et al., (2003), uses 5 phases to facilitate the literature review process, namely planning, searching, screening, extraction, and synthesis, including reporting.

The researcher tries to make a plan in the research to be able to define the question. The review question in this study is "What is the application of the user Behavior Intention using the UTAUT2 Model?". The answer to this research question will facilitate the content and see the theory and practice that occur. The next step is to identify the research database and use the appropriate keystring on the database search for the research question.

The process of finding related articles in this research question is carried out using 1 electronic database from Scopus. The selection of this article is based on articles that give a good presentation about the application of the user Behavior Intention using the UTAUT2 Model, and related empirical research. The selection of keywords used in this study is "Unified Theory of Acceptance and Use of Technology" AND "behavioral intention" AND UTAUT2. Researchers use these keywords so they can see broadly about "Unified Theory of Acceptance and Use of Technology (UTAUT)" so that they can answer research questions from general to specific.

The results of the search from the Scopus electronic database resulted in 64 articles registered with the abstract. After that the researcher reviewed the results of the search using the research question "How is the application of the user Behavior Intention using the UTAUT2 Model?". Then the researchers conducted the article inclusion and exclusion techniques that have been determined to simplify the review of the article from the search results.

The inclusion criteria that researchers did were:

- Choose only articles in English;

- Only see articles in research papers;

- No Duplication;

- Read the Abstract which contains an explanation that matches the research question;

- Articles that show empirical research methods.

Exclusion Criteria that researchers do are:

- Do not choose articles other than English;

- Issue articles other than research papers (such as magazines, books, conference papers, proceeding papers, audio / video, Thesis / dissertation);

- Articles that do not fit the research question;

- There is Duplication.

Based on the results of the screening criteria above, the researcher got 64 articles from the results of the inclusion for the keystring search with a research question in the form of "How is the application of the user Behavior Intention using UTAUT2 Model" as a technique in general search, then the researcher does the inclusion again in accordance with the 
research question only look for themes for user Behavior Intention using the UTAUT2 Model only.

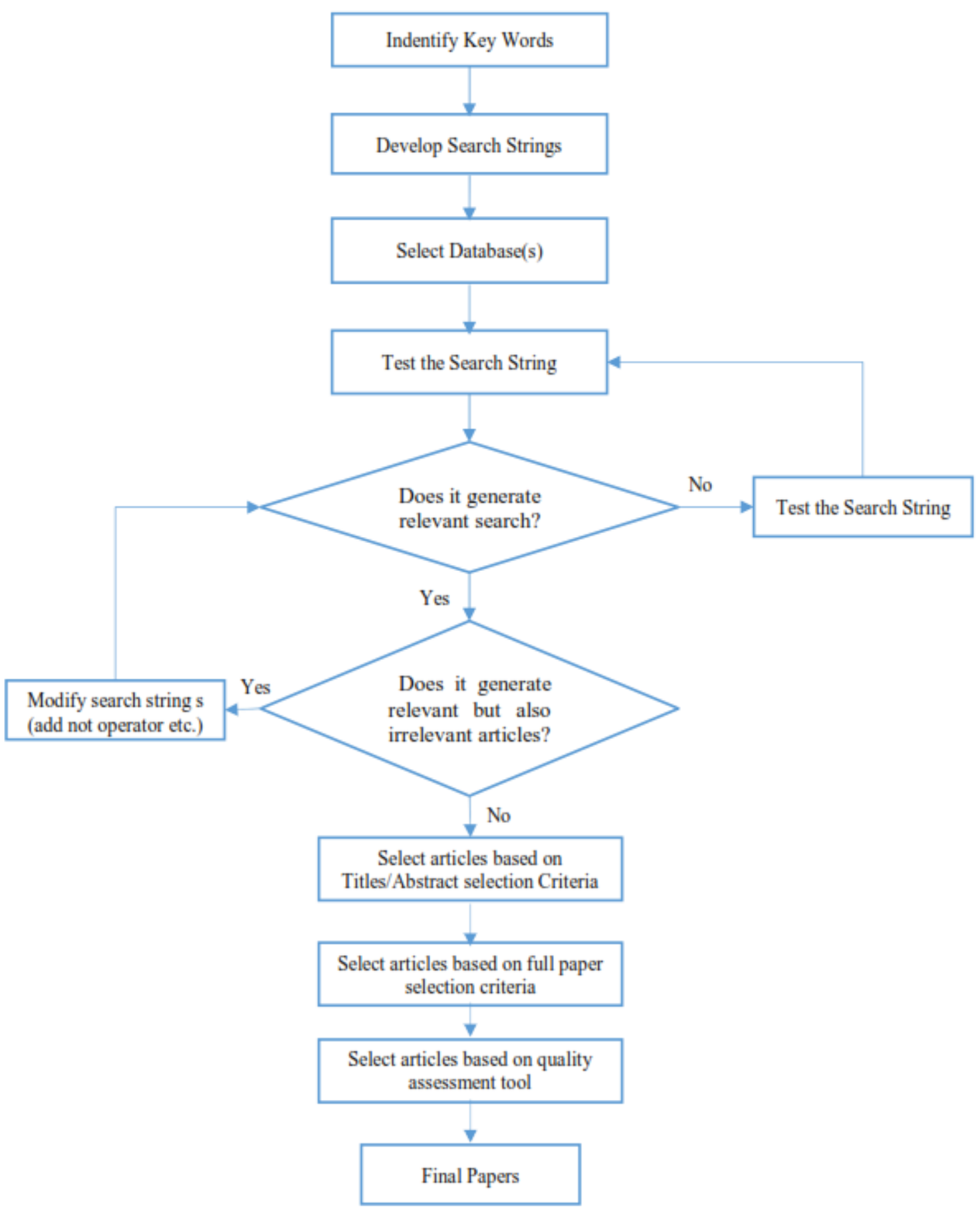

Figure 1 - Literature search process (Source: Chandorkar, 2013)

So researchers only get 20 articles that specifically answer from the research question. this states that research on user Behavior Intention using UTAUT2 Model is still a lot of experimental processes and is still testing the theory. Researchers deliberately look in general to see the method and also the theoretical basis used in general research. From these results the researchers conducted an in-depth review as outlined in Excel as the Inclusion database. The database using Excel is useful for being able to know and dissect the article in a structured manner and can make comments in the form of columns available 
in Excel (Tranfield et al., 2003), With the use of an Excel column, researchers can classify information on aspects in the article. The information that researchers do is to classify articles in the form of Title, Author, Publisher, and year of publication. After doing this the researcher also made a grouping of paper types, research design, research method, and locus of the research. The next stage is the most important in making this article is to look at the purpose of the research, the definition of the research, keywords, theory used within the research, aspects, and analyzed units will be performed. The focus of this study is to look at the unit of analysis from previous research on user Behavior Intention using the UTAUT2 Model.

\section{RESULTS OF STUDY}

This section will explain the findings of systematic reviews that have been identified and are in the process of inclusion based on group criteria in the Excel database. Researchers will explain the findings of the article from the year and the publication of as many as 20 articles that specifically address the research question.

Based on the research findings, it is known that the beginning of the article published by year, namely the use of the theory of UNTAUT2 in 2012 in the journal of Venkatesh et al., (2012) from the publication of MIS Quarterly. While the most research in using this theory is in 2018 as many as 8 articles and in 2013 no articles were detected in the search in the Scopus electronic database. There are 2 journals published from Telematics and Informatics about UNTAUT2. The rest of the research on user Behavior Intention using UTAUT2 The model was published in a variety of different journals where all of these articles are included in the research question.

Based on the classification of the systematic literature review, researchers conducted a classification based on the paper type from Petersen et al. (2008) where there are 6 categories of research paper facets, namely:

- Validation Research: These techniques are investigated and have not yet been implemented in practice. Techniques used are for example experiments, i.e., work done in the lab;

- Evaluation Research: These techniques are implemented in practice and an evaluation of the technique is conducted. That means, it is shown how the technique is implemented in practice (solution implementation) and what are the consequences of the implementation in terms of bene $\mathrm{fi}$ ts and drawbacks (implementation evaluation). This also includes identifying problems in the industry;

- Solution Proposal: A solution for a problem is proposed, the solution can be either novel or a significant extension of an existing technique. The potential benefits and the applicability of the solution are shown by a small example or a good line of argumentation;

- Philosophical Papers: Papers sketch a new way of looking at existing things by structuring the fi eld in the form of a taxonomy or conceptual framework;

- Opinion Papers: These papers express the personal opinion of somebody whether a certain technique is good or bad, or how things should have been done. They don't rely on related work and research methodologies;

- Experience Papers: Experience papers explain on what and how something has been done in practice. It has the personal experience of the author.

Based on the results of previous research findings, there are 7 validation research articles, namely from Alalwan et al., (2018), Lallmahomed et al., (2017), Herrero et al., (2017), Khan et al. (2017), Tandon et al., (2016), Ain et al., (2015), and Venkatesh et al., (2012). For articles in the form of evaluation research there are 12 articles, from Mütterlein et al., (2019), Siahaan \& Legowo, (2019), Goularte et al., (2018), Chopdar et al., (2018), Verkijika, (2018), Baabdullah, (2018), Makanyeza \& Mutambayashata, (2018), Kranthi \& Ahmed, (2018), Alalwan et al., (2017), Indrawati \& Marhaeni, (2015), Hew et al., (2015), and Wong et al., (2015). While there is only one research in the form of philosophical paper, from 
Ameen \& Willis, (2018). All of these journals use the basic theory of UNTAUT 2 and use research design using SEM-PLS, except for one study by Siahaan \& Legowo, (2019) using the SPSS Amos 22.

The application of user Behavior Intention using the UTAUT2 Model is a theory of Venkatesh et al., (2003) and later developed Venkatesh et al., (2012) which seeks to be oriented to the consumer technology acceptance and use context. In this research, it was found that there are two things that drive in UNTAUT2, namely variables in the form of hedonic motivation and price value. Hedonic motivation is an important determinant of behavioral intention and is something that can encourage performance expectancy, especially for non-organizational contexts. Researchers add moderator variables in the form of individual characteristics, namely gender, age, and experience; jointly moderate the effect of hedonic motivation on behavioral intention. of age and gender on the relationship between price value and intention.

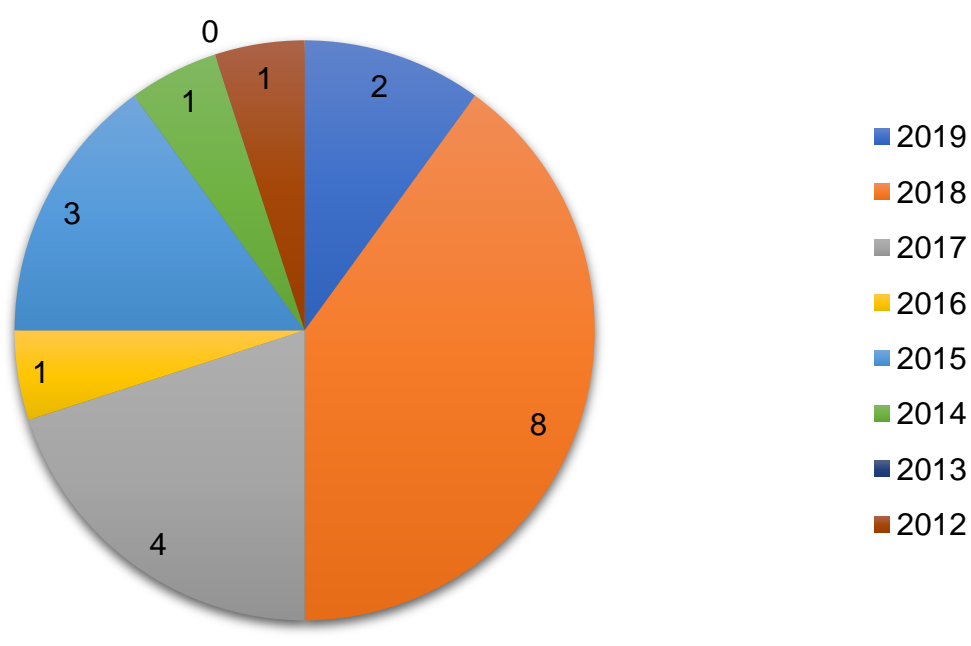

Figure 2 - Years of Articles Publications

The research by Mütterlein et al., (2019) is the latest research that uses UTAUT2 on the use of technology for innovative mobile gaming augment reality app by adding moderating variables in the form of lead-users which are assumed "product users who experience strong needs for a given new product earlier than the majority of its target market and who is expected to benefit significantly from a solution to those needs "towards the formation of behavioral intention. The variables used in this study are effort expectancy, performance expectancy, social influence, facilitating conditions, hedonic motivation, price value, and habit on behavioral intention. This study was a quantitative study with 273 participants that technology users differed from that of non-lead-users to students from various educational backgrounds in various cities in Germany and tried augment reality games by completing various missions. After completing the predefined route, the students received a link to an online survey. The results of this study are lead-usership has effects beyond idea creation and that lead-usership is a relevant factor for acceptance and use of research in the context of media innovation evaluation.

The following research is a development of UTAUT2 results from Venkatesh et al., (2012) by adding additional variables in the form of moderator variables such as those from Mütterlein et al., (2019) which adds lead-user variables, where lead-users experience a need that other users will have at a later point in time and expect high benefits from finding a solution to this need. Siahaan \& Legowo, (2019) examines the online transportation App in Batam Area by adding moderator variables in the form of gender, age, experience and voluntary of use, while the construct used in this study is performance expectancy, effort 
expectancy, facilitating conditions, price value, information quality, system quality, service quality, behavioral intention, user satisfaction and behavior. Chopdar et al., (2018) added a moderator variable in the form of Consumer's perceived risk: Privacy Risk and Security Risk in the use of the UNTAUT2 theory in mobile shopping apps in India and the USA. Verkijika, (2018) added moderator variables in the form of perceived risk and perceived trust in research on smartphone applications to facilitate m-commerce activities in Cameroon. Lallmahomed et al., (2017) research about e-government services adoption in a small island developing state in Mauritius, researchers see a moderator variable in the form of Resistance to change, where the result is an improvement in information quality and design technology will increase the security variable and privacy, increasing trust and reducing resistance to change. Research from Alalwan et al., (2017) added the variable of trust in researching about Jordanian internet banking customers. The results of the study were that the performance expectancy, effort expectancy, hedonic motivation, price value and trust variables had a significant and positive effect on behavioral intention. Tandon et al, (2016) added the COD mode of Payment variable and moderator variable in the form of Perceived risk: which consists of Financial risk, product performance risk, social risk, time risk, security risk. The findings of this study reveal that perceived risk has a relationship negative with behavioral intention, while drivers were positively associated with behavioral intention, while research not mentioned here adopts all variables from UNTAUT2 Venkatesh et al., (2012). while research from Ameen \& Willis, (2018) is a conceptual study using variables relatively new variables from the concept of UNTAUT2, namely in the form of Effort Expectancy, Perceived relative advantage (usefulness), Enjoyment, Technological culture, price value, Social influence, Culture specific beliefs and values, National IT Development, Habit, Facilitating conditions after seeing the condition of the user smartphones and the actual use of smartphones by young Arabs consumers in three Arab countries: Iraq, Jordan, and the United Arab Emirates (U.A.E.). the findings of this study conclude that young people in Arabic do not object to meetings that are mediated by technological convenience. Therefore this technology provider enables the full use of mobile messaging applications that facilitate these meetings, such as Skype, Viber, FaceTime, and WhatsApp.

All of the literature review results from this study use quantitative methods with SEMPLS as a tool to use surveys to collect large amounts of consumer data on the use of technology with theoretical assistance from the UTAUT2 Model to see their impact on behavioral intention.

\section{CONCLUSION}

This research was conducted using systematic literature review with the intention to answer the research question in the form of "How is the application of the user Behavior Intention using the UTAUT2 Model?". Researchers collect various articles and do inclusions to answer the criteria of the research questions. the result is 20 articles found from the Scopus electronic database. The first research about user Behavior Intention using UTAUT2 The model was detected starting in 2012 and starting to develop the following year.

The results of the literature review findings found that all previous studies were quantitative studies using survey methods. This is a research with validation and evaluation research where this research is still trying to implement and evaluate real conditions. This shows that research from this field is still fairly new and appealing because researchers want to examine empirical research can understand the situation in shaping the user Behavior Intention using the UTAUT2 Model. In this study there are findings of research to facilitate researchers and practitioners in the future.

Researchers suggest using Empirical research that can be done in the future is to use a theoretical framework from the Unified Theory of Acceptance and Use of Technology (UTAUT) 2 model base on customers context from Venkatesh et al., (2012). With additional modification of variables from Mütterlein et al., (2019), Siahaan \& Legowo, (2019), Chopdar et al., (2018), Verkijika, (2018), Kranthi \& Ahmed (2018), Alalwan et al., (2017), Tandon et al., (2016), and explanatory research from Ameen \& Willis, (2018). 


\section{REFERENCES}

1. Ain, N., Kaur, K., \& Waheed, M. (2015). The influence of learning value on learning management system use: An extension of UTAUT2. Information Development 1-16, 1(16). https://doi.org/10.1177/0266666915597546.

2. Ajzen, I. (1991). The theory of planned behavior. Orgnizational Behavior and Human Decision Processes, 50, 179-211. https://doi.org/10.1016/0749-5978(91)90020-T.

3. Alalwan, A. A. (2020). International Journal of Information Management Mobile food ordering apps: An empirical study of the factors affecting customer e-satisfaction and continued intention to reuse. International Journal of Information Management, 50(February 2019), 28-44. https://doi.org/10.1016/j.ijinfomgt.2019.04.008.

4. Alalwan, A. A., Dwivedi, Y. K., \& Rana, N. P. (2017). International Journal of Information Management Factors influencing adoption of mobile banking by Jordanian bank customers: Extending UTAUT2 with trust. International Journal of Information Management, 37(3), 99-110. https://doi.org/10.1016/j.ijinfomgt.2017.01.002.

5. Alalwan, A. A., Dwivedi, Y. K., Rana, N. P., \& Algharabat, R. (2018). Examining factors influencing Jordanian customers' intentions and adoption of internet banking: Extending UTAUT2 with risk. Journal of Retailing and Consumer Services, 40(July 2017), 125-138. https://doi.org/10.1016/j.jretconser.2017.08.026.

6. Ameen, N., \& Willis, R. (2018). A generalized model for smartphone adoption and use in an Arab context: A cross-country comparison cross-country comparison. Information Systems Management, 35(3), 254-274. https://doi.org/10.1080/10580530.2018.1477300

7. Baabdullah, A. M. (2018). Technology in Society Consumer adoption of Mobile Social Network Games (M-SNGs) in Saudi Arabia: The role of social influence, hedonic motivation and trust. Technology in Society, 1(12). https://doi.org/10.1016/j.techsoc.2018.01.004.

8. Chan, K. Y., Gong, M., Xu, Y., \& Thong, J. Y. L. (2008). "Examining User Acceptance of SMS: An Empirical Study in China and Hong Kong." Proceedings of 12th Pacific Asia Conference on Information System, Suzhou, China, July 3-7.

9. Chandorkar, P. (2013). A Systematic Review of The Determinants and the Behaviour of Equity Risk Premium. (P. S. Poshakwale, Ed.). Cranfield University.

10. Chopdar, P. K., Korfiatis, N., Sivakumar, V. J., \& Lytras, M. D. (2018). Mobile shopping apps adoption and perceived risks: A cross-country perspective utilizing the Unified Theory of Acceptance and Use of Technology. Computers in Human Behavior. https://doi.org/10.1016/j.chb.2018.04.017.

11. Denyer, \& Tranfield. (2003). Towards a methodology for developing evidence informed management knowledge by means of systematic review. British Journal of Management, 14, 207-222.

12. Goularte, A. C., Zilber, S. N., Goularte, A. C., Julho, U. N. De, Paulo, S., Zilber, S. N., ... Andre, S. (2018). The moderating role of cultural factors in the adoption of mobile banking in Brazil factors. International Journal of Innovation Science. https://doi.org/10.1108/IJIS-11-2017-0119.

13. Herrero, Á., Martín, H. S., \& Salmones, M. del M. G. de los. (2017). Explaining The Adoption Of Social Networks Sites To Share User-Generated Content: A Revision of The Utaut2. Computers in Human Behaviour. https://doi.org/10.1016/j.chb.2017.02.007.

14. Hew, J.-J., Lee, V.-H., Ooi, K.-B., \& We, J. (2015). What catalyses mobile apps usage intention: An empirical analysis. Industrial Management \& Data Systems, 115(7).

15. Indrawati, \& Marhaeni, G. A. M. (2015). Measurement for analyzing istant messenger application adoption using Unified Theory of Acceptance and Use of Technology 2. International Business Management, 9(4), 391-396.

16. Khan, I. U., Hameed, Z., Khan, S. U., \& Beijing, T. (2017). Understanding Online Banking Adoption in a Developing Country: UTAUT2 with Cultural Moderators. Journal of Global Information Management Volume 25, Issue 1, January-March 2017, 25(1), 43-65. https://doi.org/10.4018/JGIM.2017010103. 
17. Kranthi, A. K., \& Ahmed, K. A. A. (2018). Determinants of smartwatch adoption among IT professionals - an extended UTAUT2 model for smartwatch enterprise. International Journal Enterprise Network Management, 9(3/4), 294-316.

18. Lallmahomed, M. Z. I., Lallmahomed, N., \& Lallmahomed, G. M. (2017). Factors influencing the adoption of e-Government Services in Mauritius. Telematics and Informatics. https://doi.org/10.1016/j.tele.2017.01.003.

19. Makanyeza, C., \& Mutambayashata, S. (2018). Consumers' acceptance and use of plastic money in Harare, Zimbabwe: Application of the unified theory of acceptance and use of technology 2. International Journal of Bank Marketing, 36(2), pp.379-392. https://doi.org/10.1108/lJBM-03-2017-0044.

20. Mütterlein, J., Kunz, R. E., \& Baier, D. (2019). Technological Forecasting \& Social Change Effects of lead-usership on the acceptance of media innovations: A mobile augmented reality case. Technological Forecasting \& Social Change, 145(April 2017), 113-124. https://doi.org/10.1016/j.techfore.2019.04.019.

21. Nugroho, D., Purnomo, M., Hermanto, B., \& Maulina, E. (2019). Social Entrepreneurship Intention: A Systematic Literature Review. RJOAS, 4(88), April 2019, 4(April), 86-94. https://doi.org/10.18551/rjoas.2019-04.12.

22. Petersen, K., Feldt, R., Mujtaba, S., \& Mattsson, M. (2008). Systematic Mapping Studies in Software Engineering. 12Th International Conference on Evaluation and Assessment in Software Engineering, 17, 10. https://doi.org/10.1142/S0218194007003112.

23. Siahaan, M., \& Legowo, N. (2019). The Citizens Acceptance Factors of Transportation Application Online In Batam: An Adaptation Of The Utaut2 Model And Information System Success Model. Journal of Theoretical and Applied Information Technology, 97(6), 1666-1676.

24. Tandon, U., Kiran, R., \& Sah, A. N. (2016). Understanding Online Shopping Adoption in India: Unified Understanding Online Shopping Adoption in India: Unified Theory of Acceptance and Use of. Service Science, 8(4)(November), 420-437.

25. Venkatesh, V., Morris, M. G., Davis, G. B., \& Davis, F. D. (2003). User Acceptance of Information Technology: Toward A Unified View. MIS Quarterly Vol. 27 No. 3, Pp. 425478/September 2003, 27(3), 425-478.

26. Venkatesh, V., Thong, J. Y. L., \& Xu, X. (2012). Consumer Acceptance and Use of Information Technology: Extending the Unified Theory of Acceptance And Use of Technology. MIS Quarterly Vol. 36 No. 1 Pp. 157-178/March 2012, 36(1), 157-178.

27. Verkijika, S. F. (2018). Telematics and Informatics Factors influencing the adoption of mobile commerce applications in Cameroon. Telematics and Informatics, (September 2017), 0-1. https://doi.org/10.1016/j.tele.2018.04.012.

28. Wong, C.-H., Tan, G. W.-H., Loke, S.-P., \& Ooi, K.-B. (2015). Mobile TV: a new form of entertainment?". Industrial Management \& Data Systems, 114(7), 1050-1067. https://doi.org/http://dx.doi.org/10.1108/IMDS-05-2014-0146. 